\title{
Therapeutic Uses of Traditional Chinese Medicines Against COVID-19
}

\author{
Manal Buabeid $\mathbb{D}^{1,2, *}$ \\ Munazza ljaz ${ }^{3, *}$ \\ Saba Shamim ${ }^{3}$ \\ Xianju Huang (D) ${ }^{4}$ \\ Ghulam Murtaza (iD ${ }^{5}$ \\ 'College of Pharmacy and Health \\ Sciences, Ajman University, Ajman, 346, \\ United Arab Emirates; ${ }^{2}$ Medical and Bio- \\ allied Health Sciences Research Centre, \\ Ajman University, Ajman, United Arab \\ Emirates; ${ }^{3}$ Institute of Molecular Biology \\ and Biotechnology, The University of \\ Lahore, Lahore, Pakistan; ${ }^{4}$ College of \\ Pharmacy, South-Central University for \\ Nationalities, Wuhan, 430074, People's \\ Republic of China; ${ }^{5}$ Department of \\ Pharmacy, COMSATS University \\ Islamabad, Lahore Campus, Lahore, \\ 54000, Pakistan
}

*These authors contributed equally to this work
Correspondence: Ghulam Murtaza;

Saba Shamim

Tel +923215129950

Fax +92 992-38344।

Email gmdogar356@gmail.com;

sabashamimgenetics@gmail.com

\begin{abstract}
COVID-19 is a pandemic and a serious respiratory disorder that is caused by coronavirus. It has produced an outbreak of acute infectious pneumonia in China and afterward all around the world. There is not a single anti-viral drug, vaccine or any kind of treatment available for this fatal disease. There are only a few options available for symptomatic relief. Thus, in China, $85 \%$ of SARS-CoV-2 infected individuals have been treated with traditional Chinese medicines (TCM). Thus, this article focused on the previous kinds of literature regarding COVID-19 and its treatment with TCM along with its applications. SARS-CoV-2 and SARS-CoV showed similarity in genes, pathological processes, and epidemiology, so these can be treated with TCM. The proof regarding treatment of SARSCoV with TCM explicitly shows the advantages of using TCM therapy for COVID-19. Present literature explains the mode of action and efficacy of TCM and elaborates on the natural compounds introduced to treat COVID-19.
\end{abstract}

Keywords: mode of action, efficacy, TCM, antivirals, COVID-19, respiratory pneumonia

\section{Background of COVID-I 9}

A sudden outbreak of serious respiratory pneumonia started in Wuhan city, Hubei province of China in December 2019, ${ }^{1}$ which on 7 January 2020, was declared as a resistant strain of coronavirus termed SARS-CoV-2. ${ }^{2}$ Thus on 11 February 2020, this unexplainable pneumonia was called, by the World Health Organization, Coronavirus Disease-2019 (COVID-19). ${ }^{3}$ COVID-19 symptoms include flu-like symptoms, fever, cough, along common respiratory disorder including lung damage while minor symptoms include diarrhea, fatigue and myalgia., ${ }^{4,5}$ On 17 February 2020, China reported a total of 72,332 cases of COVID-19. ${ }^{6}$ The spread rate of COVID-19 was very fast, every single day, the cases with COVID-19 reported were multiplied compared to the previous day. It is transmitted through human to human via coughing, sneezing and even touching. On gene examination, SARS-Co-2 appeared as an enveloped $\beta$-coronavirus with single-stranded RNA . ${ }^{7}$ The genomic comparison of SARS-CoV-2 with SAR-CoV showed 79.5\% similarity in the genomic sequence. Furthermore, both SARS-CoV-2 and SAR-CoV use spike (S) proteins to enter into human alveolar epithelial cells, which bind to angiotensinconverting enzyme 2 (ACE2) receptor in humans. ${ }^{8}$

Several major techniques are available to diagnose COVID-19, such as lab testing and chest radiograph but unluckily, there are not any vaccines or antivirals present for the sake of treatment. ${ }^{9}$ Thus China reported its current clinical guidelines to treat COVID-19 or Middle East Respiratory Syndrome (MERS), and 
according to that traditional Chinese medicines (TCM) and traditional medicines are presently the only way to treat COVID-19. ${ }^{10}$ This literature covers the TCM treatment in the context of current conventional management to treat COVID-19 patients. It was already documented in $2002-2003^{11}$ that TCM therapy had been used to treat SARS-CoV infected individuals and with the outbreak of COVID-19, it was found that COVID-19 showed identical genomic sequence, pathological processes, and epidemiology as SARS-CoV. ${ }^{8}$ Thus, results obtained after TCM treatment were evaluated on the molecular basis and lab studies which give the benefits of using TCM treatment in combating COVID-19.

\section{Scope of TCM Against COVID-I 9}

As there is no specific treatment available to treat COVID19 , it is necessary to adopt some supportive therapy to combat the risk of the disease. It includes antivirals (lopinavir, ritonavir, ribavirin, favipiravir, remdesivir, oseltamivir, chloroquine, and interferon), broad-spectrum antibiotics (amoxicillin, azithromycin, and fluoroquinolones), ${ }^{12}$ corticosteroids, $^{7}$ and convalescent plasma. ${ }^{22}$ Thus, SARSCoV-2 infected individuals were treated with HIV protease inhibitors ritonavir and lopinavir along with antibiotics or IFN $\alpha-2 b .{ }^{13}$ Besides, ribavirin (nucleoside analogs) was also found to be useful in treating COVID-19 as it was already documented to treat infections produced by a syncytial virus (RSV), ${ }^{14}$ MERS and SARS-CoV. Still, its use is limited due to its disadvantage of causing anemia and whether the antiviral spectrum of ribavirin covers SARS-CoV-2 infection is still not clear. Favipiravir (T-705), another nucleoside analog, can exclusively treat influenza due to RNA polymerase of RNA virus. ${ }^{15} \mathrm{~A}$ current in vivo study regarding favipiravir documented its activity against SARS-CoV-2, ${ }^{16}$ but still, in vivo effects of favipiravir are not clear. Another antiviral drug that might show the most suitable results against SARS-CoV-2 is remidesivir. It shows promising in vitro and in vivo activity against a wide range of SARS and MERS viruses, ${ }^{17}$ and also showed a tendency of viral suppression and improved lung condition in animal models. ${ }^{18}$ According to another study, SARS-CoV-2 infection could be inhibited in Vero E6 cells when treated with remdisivir, and the first US infected patient had simultaneously ameliorated symptoms induced by COVID-19 following administration of remdesivir intravenously. However, presently, remdesivir is still undergoing clinical trials to evaluate its potency and safety against COVID19. ${ }^{19}$ Another antiviral drug, oseltamivir, has also been found useful in treating COVID-19, while its potency is still vague.

Chloroquine is also categorized as a broad-spectrum antiviral drug. ${ }^{20}$ It shows potent activity against COVID$19 .^{16}$ To evaluate its potency, an open-label clinical trial $\left(\right.$ ChiCTR2000029609) ${ }^{21}$ has been started to find out its clinical efficacy. IFNa (5 million U), is an antiviral atomization inhaler used to treat SAR-CoV-2. ${ }^{12}$ A trial was started, which contained IFN $\alpha-2 b$ as well as anti-HCV inhibitor, ${ }^{13}$ but the results did not clearly show the combined effect of antiviral and IFN $\alpha-2 b$.

Corticosteroids were also used as adjuvant therapy, though it may not decrease the mortality rate of SARS$\mathrm{CoV}$ and MERS-CoV, ${ }^{22}$ it could decrease the increased level of cytokines in patients due to COVID-19 which leads to suspended viral clearance. ${ }^{23}$ As a result, corticosteroids are not recommended treatment strategies to treat COVID-19. ${ }^{24}$

The role of convalescent plasma treatment was already known and being used in the treatment of severe kinds of influenza or coronavirus disease due to its capability to reduce viral load and mortality rate. ${ }^{25}$ Convalescent plasma was used in China under the careful monitoring of health care professionals.

WHO has concluded that there is not a single antiviral or vaccine available so far to treat COVID-19. ${ }^{26}$ Supportive therapy of TCM has been used for centuries. There is room for intervention that TCM could be used as complementary medicine for COVID-19 therapy. It was also found that TCM therapy was chosen as a helpful measure taken to treat coronavirus disease, in additon, it helped to diminish the adverse effects produced by other conservative treatments. Thus, TCM can be considered as a valued weapon to treat coronavirus disease.

The clinical evidence of using TCM against SARSCoV-2 has the background of using TCM therapy as a treatment strategy for SARS-CoV in 2002, when there was a SARS coronavirus outbreak in Guangdong (China) until 2003 , of which there were 8000 cases worldwide. ${ }^{27}$ Several hundred case reports, studies, and clinical trials were carried out to analyze the effect of TCM on SARS. According to that, pieces of evidence proved the favorable effects of TCM in the treatment of SARS. Therefore, counting Singapore and Hong Kong came up with a mortality rate of up to $18 \%$.

On the other hand, the mortality rate in Beijing was very high, almost up to $52 \%$ on the 5th of May and until 20 th May 2003, the mortality rate was reduced up to $4 \%$ to 
$1 \%$. It was believed that a sudden decrease in mortality rate in Beijing was due to the use of TCM as a supportive therapy rather than using conservative therapy. ${ }^{28}$ In 2002 when an outbreak of SARS occurred, Lau et al documented the effect of TCM therapy as a prophylactic measure and stated that Sang Ju Yin plus Yu Ping Feng San did not induce infection in 1063 hospital employees as compared to induction of $0.4 \%$ of individuals in the control group. It was considered from proof that the combination of $\mathrm{Yu}$ Ping Feng San and Sang Ju Yin can increase host immunity by stimulating T-cells. ${ }^{29}$ Compared to controlled trials, TCM therapy caused a decrease in disease-related symptoms and accelerated the recovery period of patients infected with SARS. ${ }^{30}$ The efficacy of TCM as a treatment strategy was proven by lab studies. Lancet documented the research paper about the effect of TCM, for example liquorice root against SARS virus and stated that it has glycyrrhizin in the form of active constituent that inhibits the replication of SARS virus. ${ }^{31}$ Other research reported the effect of baicalin as "anti-SARS virus" and its active constituent glycyrrhizin showed antiviral activity in plaque reduction assay. ${ }^{32}$ In addition, another researcher, Wang et al, also extracted compound MOL376 from TCM, which could inhibit cathepsin L, and thus became a major compound in the treatment of SARS-virus. ${ }^{33,34}$

There are several hundred pieces of research available on TCM therapy after SARS became an epidemic in China. Thus, to prove TCM as a treatment strategy, these literature should be critically reviewed. For this purpose, Liu et al studied 8 randomized trials and concluded that the conventional medicine in combination with TCM therapy showed better results of reduced fatality rate and increased recovery period while it showed antifungal activity in SARS infected individuals. However, the adopted clinical trials were not authorized enough to be used as a treatment of choice. ${ }^{35}$ Leung reviewed 90 research papers out of 130 publications and found that the use of TCM in combination with conventional treatment was far better than conventional treatment alone, as it could control fever, improve chest congestion, and relieve other symptoms. Though these results are not sufficient enough to be used without clinical trials. ${ }^{11}$ The successive research on TCM carried out by Liu et al reported that adjuvant treatment with TCM is worthless and found no effect on mortality rate. ${ }^{35}$ Thus, to ensure the results (because of lack of sound findings of clinical trials), $\mathrm{Wu}$ et al recommended carrying out clinical trials again to treat acute infections of the respiratory tract. ${ }^{35}$

\section{Novel Ingredients in TCM Against COVID-I 9}

Most commonly, TCM uses natural products which are considered healthy sources in order to treat human diseases. Figure 1 describes various TCM, ie Yin Qiao San, ${ }^{36}$ Yu Ping Feng San, ${ }^{37}$ Sang Ju Yin and Yu Ping Feng San that is used against SARS-CoV, Lian Hua Qing Wen Capsule, ${ }^{38}$ Shuang Huang Lian, ${ }^{39}$ and Ma Xin Gan Shi Tang. ${ }^{40}$ Table 1 lists the extracts and ingredients found in herbal formulae of TCM which have specific anti-SARS-CoV activity. Thus, to find out the natural compound that inhibits SARS-CoV-2 activity, earlier studies were taken into the ground because of homology between SARS-CoV and SARS-CoV-2. Viral replication requires 3-chymotrypsin-like protease (3CLpro), thus 3CLpro is considered as the leading drug target for the development of therapies against various coronaviruses such as SARS-CoV-2. Similarly, some other herbal constituents with effective coronavirus inhibitory potential are present in TCMs (Table 2).

The most important factor for consideration for the preparation of anti-HCoV agents is the helicase proteins, which act as a target material for anti-HCoV agents. As reported by Yu et al, helicase protein of coronavirus named nsP13 was potentially targeted by myricetin and scutellarein to downregulate the synthesis of coronavirus via disrupting ATPase activity. ${ }^{46}$ RNA-dependent RNA polymerase (RdRp) is another factor considered for antiCOVID agents as it is involved in the synthesis of negative and positive strands of RNA. The experimentation with different TCM therapies explained that TCM therapy is involved in suppression of the RdRp enzyme. These include Sinomenium acutum with $\mathrm{IC}_{50}: 198.6 \mu \mathrm{g} / \mathrm{mL}$, Kang Du Bu Fei Tang with $\mathrm{IC}_{50}$ value at $471.3 \mu \mathrm{g} / \mathrm{mL}$, Coriolus versicolor with $\mathrm{IC}_{50}$ value at $108.4 \mu \mathrm{g} / \mathrm{Ml}$, and Ganoderma lucidum with $\mathrm{IC}_{50}$ at $41.9 \mu \mathrm{g} / \mathrm{mL} .{ }^{47}$ Deng et al carried out large-scale experimentation and it involved screening and identification of already mentioned medications, TCM therapy and other synthetic medication, aiming to find out the anti-COVID agents via advanced techniques like cell-based assays using SARS-CoV virus and Vero E6 cells. As a result, it was documented that growth and multiplication of SARS-CoV can be controlled by ginsenoside-Rb1, aecin, and reserpine found in Panax ginseng, horse chestnut tree, and genus Rauwolfia respectively in therapeutic concentration. ${ }^{48}$ 


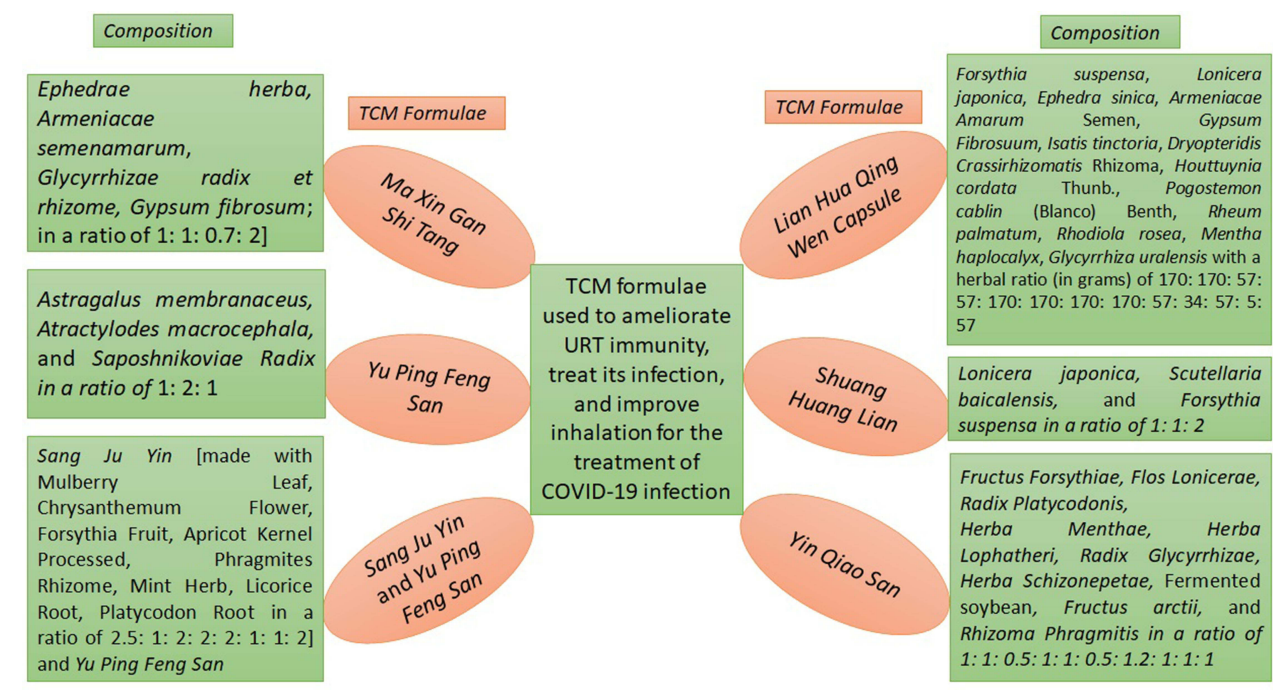

Figure I TCM decoction formulas (with their compositions) used to ameliorate URT immunity, treat its infection, and improve inhalation in the treatment of COVID-19 infection.

Just like the previously mentioned viruses, SARS-CoV2 also uses ACE2 receptors of host for its entry into the human cell. ${ }^{49}$ Thus, the traditional Chinese medicines that can target ACE2, can easily control the infection produced by SARS-CoV-2. There are several natural compounds present that interfere with any communication between SARS-CoV S proteins and ACE2, these include emodin, ${ }^{50}$ scutellarin, ${ }^{51}$ baicalin, ${ }^{52}$ Tetra-O-galloyl- $\beta$-D-glucose (TGG), and luteolin. ${ }^{53}$ Though their anti-COVID activity still needs to be evaluated. Furthermore, the viral

Table I Herbal Extracts and Active Contituents with AntiHuman Coronavirus (Anti-HCoV) Activity

\begin{tabular}{|l|l|l|}
\hline $\begin{array}{l}\text { Extract or } \\
\text { Ingredient }\end{array}$ & \multicolumn{1}{|c|}{$\begin{array}{c}\text { Herbal Extract/Active } \\
\text { Contituent }\end{array}$} & References \\
\hline Extract & $\begin{array}{l}\text { Isatis indigotica } \\
\text { Houttuynia cordata } \\
\text { Rheum palmatum }\end{array}$ & {$[41]$} \\
& Cepharanthine, fangchinoline, & {$[44]$} \\
\hline \multirow{2}{*}{ Ingredient } & tetrandrine & {$[45,46]$} \\
& Myricetin, scutellarein & {$[47]$} \\
& Glycyrrhizin & {$[48,49]$} \\
& Herbacetin, quercetin, & {$[50]$} \\
& isobavaschalcone, helichrysetin & \\
& Herbacetin, rhoifolin, pectolinarin, & {$[51-53]$} \\
& quercetin & {$[54]$} \\
& Quercetin & {$[55,56]$} \\
& Emodin & {$[57]$} \\
& Kaempferol derivatives & {$[58,59]$} \\
& Baicalin & {$[60]$} \\
\hline
\end{tabular}

discharge from infected body or cell can be controlled by inhibiting 3a ion channel, and it can be done by emodin ${ }^{54}$ and kaempferol derivatives, juglanin. ${ }^{55}$ Anti-SARS-CoV activity has also been shown by Saikosaponins, ${ }^{56}$ quercetin, TSL-1 extracted from Toona sinensis Roem, ${ }^{57}$ and glycyrrhizin, by blocking entry into a cell. ${ }^{58}$

Sometimes inflammatory reactions induced due to viral infection like SARS-CoV or COVID-19 can cause the death of patients. Thus, the use of anti-inflammatory agents can reduce the severity of a disease condition or fatality rate. ${ }^{59}$ Another study reported that they used Lonicerae japonica Fructus Forsythia Flos, and Scutellariae radix as an anti-COVID agent. ${ }^{60}$ Afterward, it was found that the mixture of these herbal compounds

Table 2 Herbal Compounds with Potential to Suppress the SARS 3CLpro and Their Reported IC50 Values

\begin{tabular}{|l|l|l|}
\hline Herbal Compounds & IC $_{\mathbf{5 0}}(\boldsymbol{\mu M})$ & References \\
\hline Sinigrin & 217 & {$[4 I]$} \\
Indigo & 752 & {$[4 I]$} \\
Aloe-emodin & 366 & {$[4 I]$} \\
Hesperetin & 8.3 & {$[4 I]$} \\
Beta-sitosterol & 1210 & {$[4 I]$} \\
Quercetin & 73 & {$[52]$} \\
Epigallocatechin gallate & 73 & {$[52]$} \\
Gallocatechin 3CLpro & 47 & {$[52]$} \\
Iguestrin & 2.6 & {$[53]$} \\
Pristimerin & 5.5 & {$[53]$} \\
Amentoflavone & 8.3 & {$[54]$} \\
3-theaflavin-3-gallate & 9.8 & {$[55]$} \\
Isatin & 0.95 & {$[56]$} \\
\hline
\end{tabular}


blocked the release of cytokines and chemokines through peripheral blood mononuclear cells which are pathologically produced due to staphylococcal toxic shock syndrome. ${ }^{61}$ A TCM, Dang Gui Long Hui Pill, has an active compound named indirubin, which showed antiCOVID effect along with an immunity-boosting effect while human macrophages infected by influenza H5N1 virus and type-I alveolar epithelial cells were being studied. ${ }^{62}$ Similarly, the influenza virus can be inhibited by using another TCM, Lian Hua Qing Wen Capsule. It works as an anti-COVID agent by inhibiting influenza at its initial stage and it also down-regulates the gene expression of MCP and IL-6, IL-8, TNF- $\alpha$, and IP- $10 .{ }^{63}$ Moreover, Dong et al also documented that Lian Hua Qing Wen Capsule has the capability to decrease the levels of IL-17, IL-23, IL-8 and TNF- $\alpha$ in sputum and also decreased the levels of IL-17 and IL- 8 in blood for the relief of COPD patients. ${ }^{39}$ Poon et al also conducted his own self-control study and concluded that Sang Ju Yin and Yu Ping Feng San may have an immunity-boosting effect against COVID-19. ${ }^{64}$ Several agents are recognized and used as anti-COVID agents but the mode of action of these agents is still obscure, just like many TCM used as antiSARS-CoV agents such as Artemisia annua, and Lindera aggregate. $^{65}$

\section{Current Scenario of TCM Efficacy in COVID-I 9 Patients}

Due to the extensive advantages of TCM therapy, the Chinese government has added it as a part of its campaign to treat SARS-CoV-2. For this purpose, TCM therapy has been announced as an official adjuvant therapy along with conventional medication by the Health Commission of 26 provinces. Up unil February 17, a total of 60,107 confirmed patients with SARS-CoV-2, ie, $85 \%$ of total cases, were treated with TCM therapy by the National Health Commission of China. ${ }^{66}$ As of 1 March 2020, 303 clinical trials have been carried out to find out the safety of TCM therapy. These trials were categorized in such a way that 50 trials $(16.5 \%)$ studied the use of TCM alone, in which 14 cases $(4.6 \%)$ gave data about the use of TCM, in combination with Western medicines. 22 clinical trials $(7.3 \%)$ calculated the effect of the mixture of different TCM formulae including Xin Guan-1 Formula, Xin Guan-2 Formula and Qing Yi-4. The other 14 cases (4.6\%) were evaluated for commercial TCM like Tan Re Qing Injection and Lian Hua Qing Wen Capsule.
National Health Commission has published 6 editions based on the guidelines so far regarding the diagnosis and treatment of COVID-19. ${ }^{67}$ The 4 th version explained the TCM system and gives details about what TCM should be given at which state of disease for the treatment of COVID-19. ${ }^{68}$ The latest version of guidelines are about various combinations of TCMs that are recommended for COVID-19, ${ }^{69}$ as mentioned in Figure 2. Luo et al ${ }^{70}$ analyzed the literature on TCM therapy used in 23 provinces of China (including Wuhan) for COVID-19 patients and concluded 10 herbs useful for the treatment of COVID patients (Figure 3). Another analysis conducted by $\mathrm{Xu}$ et $\mathrm{al}^{71}$ reported nine herbs used in 13 provinces of China for the treatment of COVID patients (Figure 3).

The National Administration of Traditional Chinese Medicine has documented a report on February 5, 2020, and according to that, 214 infected patients located in Hebei, Shaanxi, and Heilongjiang were treated with Qing Fei Pai Du Tang, and showed an efficacy rate of about $\geq 90 \%$. Out of these, $\geq 60 \%$ of patients recovered, while $30 \%$ were stable from disease. $^{72}$ Afterward, 701 infected individuals located in 10 different provinces of China were treated with Qing Fei Pai Du Tang and it was concluded that $18.5 \%$ of patients (approximately 130 patients) recovered from disease conditions while $7.27 \%$ of patients (51 patients) no longer had the symptoms of cough and fever. Moreover, 38.2\% of patients (268 patients) had improved symptoms of the disease while 30.2\% (212 patients) were stabilized. ${ }^{62}$ Yao et $\mathrm{al}^{73}$ and Lu et $\mathrm{al}^{74}$ reported the effect of Lian Hua Qing Wen Capsule against confirmed and suspected SARS-CoV-2 patients and concluded that traditional Chinese medicines have the ability to cure patients from disease condition along with the ability to boost immunity in the host.

SARS-CoV-2 acts differently in different patients, thus in some of these, minor signs often advance to septic shock that leads to multiple organ dysfunction syndromes (MODS), called cytokine storm. ${ }^{75}$ It was also found from the evidence that TCM did not only act as an immunity booster but it can also show immunosuppressive activity. In this context, Shen Fu Injection was reported by Wang et $\mathrm{al}^{76}$ to counter lung inflammation and decrease cytokine levels such as IL-6, IL-1 $\beta$, and others. Similarly, Chang et $\mathrm{al}^{77}$ observed the significant decrease in levels of TNF$\alpha$, IL-1 $\beta$, IL-8, IL-10 along with other cytokines after Re Du Ning Injection in LPS (Lipopolysaccharide) induced model of lung injury in rats. Another herb called tetrandrine was also reported as a potential inhibitor of proinflammatory responses in lipopolysaccharide-induced 


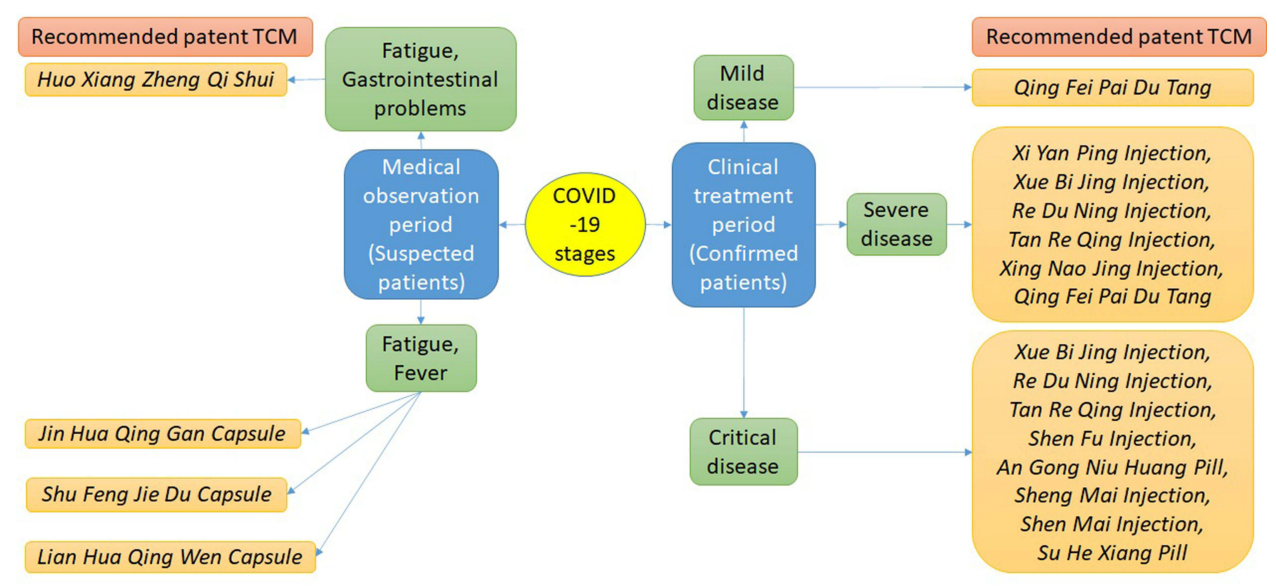

Figure 2 Recommended patent TCMs for COVID-19 treatment.

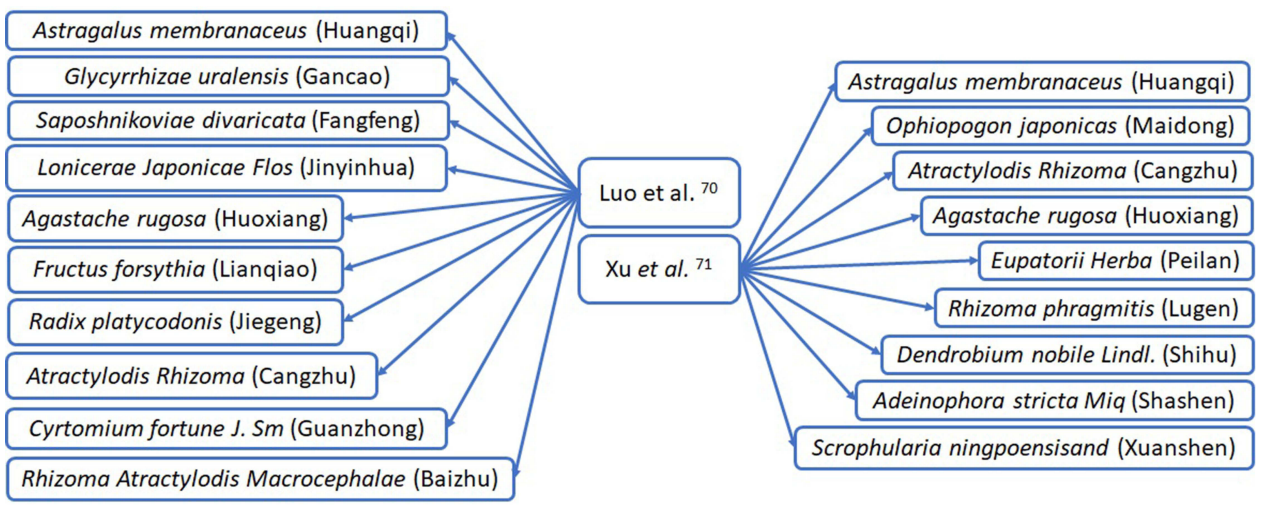

Figure 3 TCM therapies used in China for the avoidance of COVID-19 infection.

mice. ${ }^{78}$ Thus TCM, which is involved in combating cytokine storm could also be used as a treatment for COVID19 infected individuals.

In modern times, laboratory studies have neglected the clinical advantages of TCM therapy in treating COVID-19. However, some researchers started working on it to establish treatment for the disease. For this purpose, an in-vitro study has been carried out to establish its activity against SARS-CoV-2 by using Shuang Huang Lian Oral Liquid. ${ }^{55}$ Though the specific clinical trials have not been carried out so HNC'S Guidelines did not recommend this TCM preparation. ${ }^{62}$ SARS-CoV-2 uses the ACE2 receptor just like SARS-CoV to enter a cell. ${ }^{8}$ Thus hypothetically, ACE2 blockage should inhibit SARS-CoV-2 infection. Chen and $\mathrm{Du}^{79}$ accomplished an experiment with molecular docking study and found that extracted TCM compounds such as hesperetin, scutellarin, glycyrrhizin, nicotianamine and baicalin can interfere with ACE2 enzyme. ${ }^{79}$ Qing-Fei-Pai-Du decoction ${ }^{80,81}$ and other TCMs as well as their active natural compounds such as glycyrrhizic $\operatorname{acid}^{82}$ play critical roles in ameliorating COVID-19 symptoms through a variety of mechanisms. ${ }^{83}$ TCMs exhibit anti-inflammatory, immunoregulatory, and antiviral effects resulting in the protection of target organs in COVID-19 management. This phenomenon involves the interaction of numerous compounds with multiple protein targets through multiple pathways, as portrayed in Figure 4. ACE2 and $3 \mathrm{CL}$ are likely the direct target proteins for the suppression of SARS-CoV-2. Various active ingredients of TCMs such as luteolin, naringenin, wogonin, kaempferol, isorhamnetin, quercetin, and baicalin could be the interacting moieties with ACE2 and $3 \mathrm{CL}$ proteins. This interaction could be responsible for the inhibition of inflammatory mediators, regulation of immunity, 


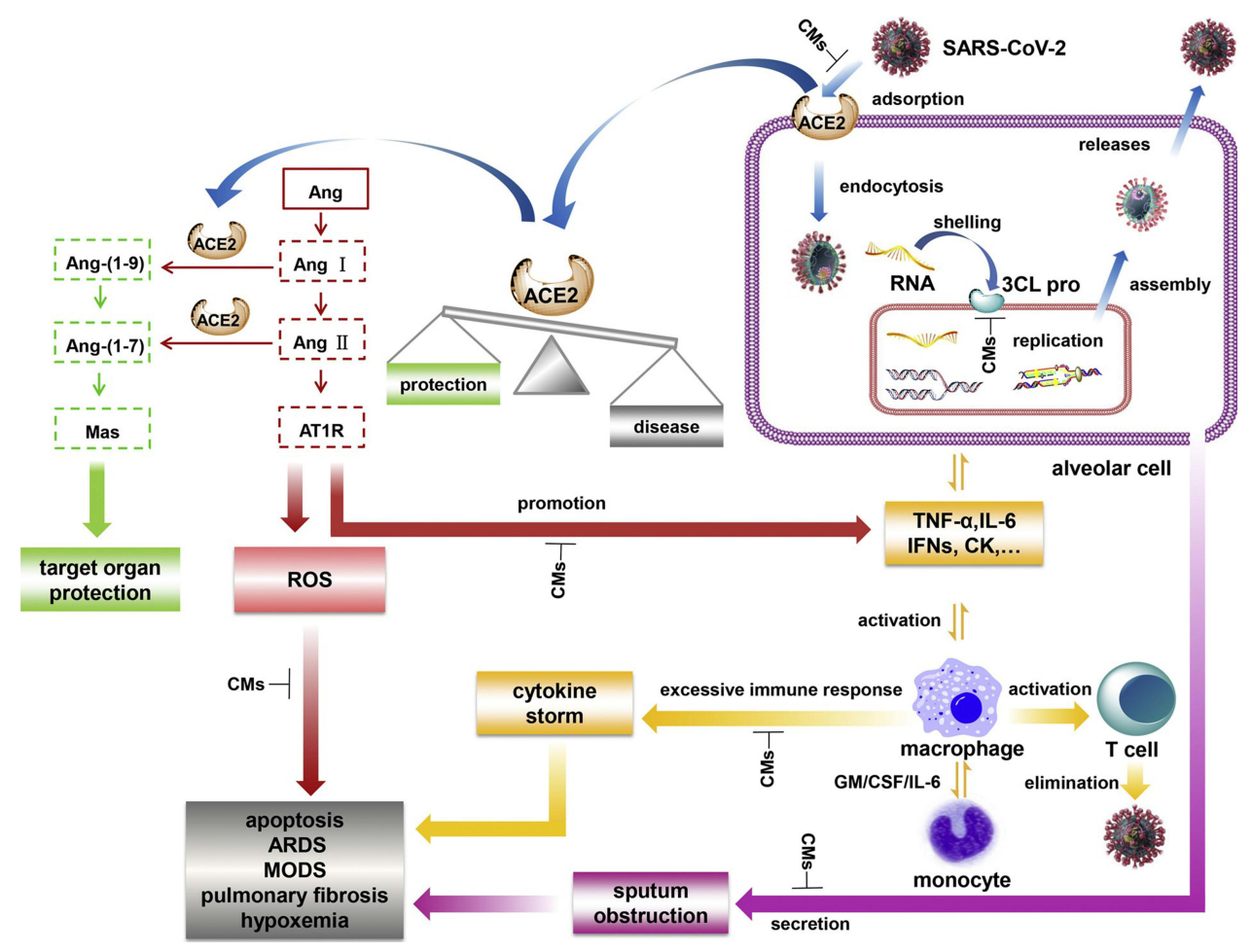

Figure 4 Mode of TCM action in a course of COVID-19 treatment. Blue arrows: Chinese medicines (CMs) might directly inhibit SRAS-CoV-2 adsorption and replication by interfering with virus' binding to ACE2 and $3 \mathrm{CL}$ pro. CMs can also indirectly protect target organs by inhibiting the binding of SARS-CoV-2 to ACE2, regulating the balance of ACE2 in the body through the Ang/Mas pathway. Red arrows: CMs might reduce the production of inflammatory mediators, protect target organs, and relieve the deterioration caused by COVID-19 by anti-inflammatory and anti-oxidant effects through affecting the Ang/ATIR pathway. Yellow arrows: CMs might play an antiinflammatory and immune regulatory role to prevent cytokine storm. Purple arrows: CMs also have an expectorant effect for relieving airway obstruction.

Notes: Reprinted from: Huang YF, Bai C, He F, Xie Y, Zhou H. Review on the potential action mechanisms of Chinese medicines in treating Coronavirus Disease 2019 (COVID-19). Pharmacol Res. 2020;158:104939. doi: 10.1016/j.phrs.2020.104939. ${ }^{83}$ Copyright (C) 2020 Elsevier Ltd. All rights reserved. With permission from Elsevier.

and elimination of free radicals via interleukins, COX-2 and MAPK in the signaling channels of interleukins, TNF, and NF$\kappa \mathrm{B}^{83}$

\section{Conclusion}

TCM therapy has always remained a treatment option in an endemic and pandemic situation of any disease just like COVID-19. TCM has always presented itself as an adjuvant therapy and is the only treatment when no other therapy is successful in treating a disease condition. There are several research publications available regarding the disease and its treatment with TCM therapy. TCM therapy has the ability to combat the present pandemic situation of SARS-CoV-2 infection, and present its true value. To enable TCM therapy to be used in practical application, randomized, double-blind and placebo-controlled trials were carried out and it is satisfactory fact that series of clinical studies are conducted to assess the potency of TCM for the treatment of COVID-19. Though these studies were not conducted according to the given standards and most of them included biases in the results. It can be expected that the recent clinical trials would be in consonance with recommended international standards and protocols as well as double-blinding study. Thus it is mandatory to use the standard products in spite of self-prepared preparations. Experimental study may help in disclosing the core mechanism involved in treating COVID-19. Further study may interestingly introduce new anti-COVID-19 moieties, which could be valuable in treating COVID-19 or related diseases. TCM safety during pandemic corona was ignored during observing the SARS patients. There are reports that herbs used in TCM include nephrotoxins and mutagens, although toxicological features of most of the Chinese herbs are not fully known yet. Further herbs used in TCM may devastate, boost, incompatible the traditional medicines. Thus, the safety of TCM in pandemic coronavirus treatment should be assessed carefully, especially to avoid elation or impede during herb-drug medication. COVID-19 progression takes place through hematologic and immunologic effects in patients, and TCMs fight on both platforms to defeat COVID-19. Nonetheless, the underlying mechanisms are largely not clear yet. The knowledge of network pharmacology could be valuable to investigate the efficacy of TCMs against COVID-19. 


\section{Abbreviations}

ACE2, angiotensin converting enzyme 2; anti-HCoV, AntiHuman Coronavirus Activity; COPD, chronic obstructive pulmonary disease; COVID-19, corona virus disease 2019; HCV, hepatitis $\mathrm{C}$ virus; HNC'S Guidelines; $\mathrm{IC}_{50}$, half maximal inhibitory concentration; IFN $\alpha$, interferon alpha; IL, interleukin; IP-10, interferon gamma inducible protein 10; LPS, lipopolysaccharide; MCP, membrane cofactor protein; MERS, Middle East Respiratory Syndrome; MODS, multiple organ dysfunction syndromes; RdRp, RNA-dependent RNA polymerase; RNA, ribonucleic acid; SARS, severe acute respiratory syndrome; SARS-CoV-2, severe acute respiratory syndrome coronavirus 2; TCM, Traditional Chinese medicine; TGG, TetraO-galloyl- $\beta$-D-glucose; TNF, tumor necrosis factor.

\section{Disclosure}

The authors report no conflicts of interest for this work.

\section{References}

1. Gralinski LE, Menachery VD. Return of the Coronavirus: 2019nCoV. Viruses. 2020;12(2):135. doi:10.3390/v12020135

2. Yu X, Li N, Dong Y. Observation on China's Strategies to prevent the resurgence of the COVID-19 epidemic. Risk Manag Healthc Policy. 2021;14:2011-2019. doi:10.2147/RMHP.S305413

3. World Health Organization. WHO director-general's remarks at the media briefing on 2019-nCoV on 11 February 2020; 2020. Available from: https://www.who.int/dg/speeches/detail/who-director-generals-remarks-at-The-media-briefing-on-2019-ncov-on-11-february-2020. Accessed November 5, 2021.

4. Guan WJ, Ni ZY, Hu Y, et al. Clinical characteristics of 2019 novel coronavirus infection in China. $N$ Engl J Med. 2020;382:1708-1720. doi:10.1056/NEJMoa2002032

5. Huang C, Wang Y, Li X, et al. Clinical features of patients infected with 2019 novel coronavirus in Wuhan, China. Lancet. 2020;395 (10223):497-506. doi:10.1016/S0140-6736(20)30183-5

6. World Health Organization. Situation report-29; 2020. Available from: https://www.who.int/docs/default-source/coronaviruse/situa tion-reports/20200218-sitrep-29-covid-19.pdf?sfvrsn=6262de9e_2. Accessed November 5, 2021.

7. Chen N, Zhou M, Dong X, et al. Epidemiological and clinical characteristics of 99 cases of 2019 novel coronavirus pneumonia in Wuhan, China: a descriptive study. Lancet. 2020;395(10223):507513. doi:10.1016/S0140-6736(20)30211-7

8. Zhou P, Yang XL, Wang XG, et al. A pneumonia outbreak associated with a new coronavirus of probable bat origin. Nature. 2020;588:E6E6. doi:10.1038/s41586-020-2951-z

9. Zumla A, Chan JF, Azhar EI, Hui DS, Yuen KY. Coronaviruses drug discovery and therapeutic options. Nat Rev Drug Discov. 2016;15:327-347.

10. Li T, Peng T. Traditional Chinese herbal medicine as a source of molecules with antiviral activity. Antiviral Res. 2013;97:1-9. doi:10.1016/j.antiviral.2012.10.006

11. Leung PC. The efficacy of Chinese medicine for SARS: a review of Chinese publications after the crisis. Am J Chin Med. 2007;35:575581. doi:10.1142/S0192415X07005077

12. Jin YH, Cai L, Cheng ZS, et al. A rapid advice guideline for the diagnosis and treatment of 2019 novel coronavirus (2019-nCoV) infected pneumonia (standard version). Mil Med Res. 2020;7:4.
13. Habibzadeh P, Stoneman EK. The novel coronavirus: a bird's eye view. Int J Occup Environ Med. 2020;11:65-71. doi:10.15171/ ijoem.2020.1921

14. Jordan PC, Stevens SK, Deval J. Nucleosides for the treatment of respiratory RNA virus infections. Antivir Chem Chemother. 2018;26:2040206618764483. doi:10.1177/2040206618764483

15. De Clercq E. New nucleoside analogues for the treatment of hemorrhagic fever virus infectionS. Chem Asian J. 2019;14:3962-3968. doi:10.1002/asia.201900841

16. Wang M, Cao R, Zhang L, et al. Remdesivir and chloroquine effectively inhibit the recently emerged novel coronavirus (2019-nCoV) in vitro. Cell Res. 2020;30:269-271.

17. Sheahan TP, Sims AC, Graham RL, et al. Broad-spectrum antiviral GS-5734 inhibits both epidemic and zoonotic coronaviruses. Sci Transl Med. 2017;9. doi:10.1126/scitranslmed.aal3653

18. Zhang L, Liu Y. Potential interventions for novel coronavirus in china: a systemic review. J Med Virol. 2020;92:479-490.

19. Holshue ML, DeBolt C, Lindquist S, et al. First case of 2019 Novel Coronavirus in the United States. N Engl J Med. 2020;382(10):929936. doi:10.1056/NEJMoa2001191

20. Savarino A, Di Trani L, Donatelli I, Cauda R, Cassone A. New insights into the antiviral effects of chloroquine. Lancet Infect Dis. 2006;6:67-69. doi:10.1016/S1473-3099(06)70361-9

21. Li G, De Clercq E, Li G, Clercq ED. Therapeutic options for the 2019 novel coronavirus (2019-nCoV). Nat Rev Drug Discov. 2020;19:149-150. doi:10.1038/d41573-020-00016-0

22. Faure E, Poissy J, Goffard A, et al. Distinct immune response in two MERS-CoV-infected patients: can we go from bench to bedside? PLoS One. 2014;9:e88716. doi:10.1371/journal.pone.0088716

23. Lai CC, Shih TP, Ko WC, Tang HJ, Hsueh PR. Severe acute respiratory syndrome coronavirus 2 (SARS-CoV-2) and Corona virus disease-2019 (COVID-19): the epidemic and the challenges. Int $J$ Antimicrob Agents. 2020;55:105924. doi:10.1016/j. ijantimicag.2020.105924

24. Stockman LJ, Bellamy R, Garner P. SARS: systematic review of treatment effects. PLoS Med. 2006;3:e343. doi:10.1371/journal. pmed.0030343

25. World Health Organization. Clinical management of severe acute respiratory infection when novel coronavirus $(2019-\mathrm{nCoV})$ infection is suspected: interim guidance, 28 January 2020; 2020. Available from: https://apps.who.int/iris/handle/10665/330893. Accessed November 23, 2021.

26. Hung IFN, To KKW, Lee CK, et al. Hyperimmune IV immunoglobulin treatment: a multicenter double-blind randomized controlled trial for patients with severe 2009 influenza A(H1N1) infection. Chest. 2013;144:464-473. doi:10.1378/chest.12-2907

27. Sohrabi C, Alsafi Z, O'Neill N, et al. World Health Organization declares global emergency: a review of the 2019 novel coronavirus (COVID-19). Int J Surg. 2020;76:71-76.

28. Tsang KWT. Severe acute respiratory syndrome. Nat Med. 2005;4:95-106.

29. Chen Z, Nakamura T. Statistical evidence for the usefulness of Chinese medicine in the treatment of SARS. Phytother Res. 2004;18:592-594. doi:10.1002/ptr.1485

30. Lau TF, Leung PC, Wong ELY, et al. Using herbal medicine as a means of prevention experience during the SARS crisis. Am J Chin Med. 2005;33:345-356. doi:10.1142/S0192415X05002965

31. Hsu CH, Hwang KC, Chao CL, et al. Can herbal medicine assist against avian flu? Learning from the experience of using supplementary treatment with Chinese medicine on SARS or SARS-like infectious disease in 2003. J Altern Complement Med. 2006;12:505-506. doi:10.1089/acm.2006.12.505

32. Cinatl J, Morgenstern B, Bauer G, et al. Glycyrrhizin, an active component of liquorice roots, and replication of SARS-associated coronavirus. Lancet. 2003;361:2045-2046. doi:10.1016/S0140-6736 (03)13615-X 
33. Chen $\mathrm{F}$, Chan $\mathrm{KH}$, Jiang $\mathrm{Y}$, et al. In vitro susceptibility of 10 clinical isolates of SARS coronavirus to selected antiviral compounds. $J$ Clin Virol. 2004;31:69-75. doi:10.1016/j.jcv.2004.03.003

34. Wang SQ, Du QS, Zhao K, et al. Virtual screening for finding natural inhibitor against cathepsin-L for SARS therapy. Amino Acids. 2007;33:129-135. doi:10.1007/s00726-006-0403-1

35. Liu X, Zhang M, He L, Li Y. Chinese herbs combined with Western medicine for severe acute respiratory syndrome (SARS). Cochrane Database Syst Rev. 2012;10:Cd004882.

36. Wu T, Yang X, Zeng X, Poole P. Traditional Chinese medicine in the treatment of acute respiratory tract infections. Resp Med. 2008;102:1093-1098. doi:10.1016/j.rmed.2008.03.015

37. Liu LS, Lei N, Lin Q, et al. The effects and mechanism of yinqiao powder on upper respiratory tract infection. Int J Biotechnol Wellness Ind. 2015;4:57-60. doi:10.6000/1927-3037.2015.04.02.2

38. Gao J, Li J, Shao X, et al. Antiinflammatory and immunoregulatory effects of total glucosides of Yupingfeng powder. Chin Med J (Engl) 2009; 122:1636-1641.

39. Dong L, Xia JW, Gong Y, et al. Effect of lianhuaqingwen capsules on airway inflammation in patients with acute exacerbation of chronic obstructive pulmonary disease. Evid Based Complement Alternat Med. 2014;2014(1-11):80. doi:10.1155/2014/637969

40. Gao Y, Fang L, Cai R, et al. Shuang-Huang-Lian exerts anti-inflammatory and anti-oxidative activities in lipopolysaccharide stimulated murine alveolar macrophages. Phytomedicine. 2014;21:461-469. doi:10.1016/j.phymed.2013.09.022

41. Xiao GL, Song K, Yuan CJ. A literature reports on the treatment of SARS by stages with traditional Chinese medicine. J Emerg Chin Med Hunan. 2005;4:53-55.

42. Yu MS, Lee J, Lee JM, et al. Identification of myricetin and scutellarein as novel chemical inhibitors of the SARS coronavirus helicase, nsP13. Bioorg Med Chem Lett. 2012;22:4049-4054. doi:10.1016/j. bmcl.2012.04.081

43. Fung KP, Leung PC, Tsui KW, et al. Immunomodulatory activities of the herbal formula Kwan Du Bu Fei Dang in healthy subjects: a randomised, double-blind, placebo-controlled study. Hong Kong Med J. 2011;17(Suppl 2):41-43.

44. Wu CY, Jan JT, Ma SH, et al. Small molecules targeting severe acute respiratory syndrome human coronavirus. Proc Natl Acad Sci U S A. 2004;101:10012-10017. doi:10.1073/pnas.0403596101

45. Kuhn JH, Radoshitzky SR, Li W, et al. The SARS Coronavirus receptor ACE 2 A potential target for antiviral therapy. In: Holzenburg A, Bogner E, editors. New Concepts of Antiviral Therapy. Boston, MA: Springer US; 2006:397-418.

46. Ho T, Wu S, Chen J, Li C, Hsiang C. Emodin blocks the SARS coronavirus spike protein and angiotensin-converting enzyme 2 interaction. Antiviral Res. 2007;74:92-101. doi:10.1016/j.antiviral.2006.04.014

47. Wang W, Ma X, Han J, et al. Neuroprotective effect of scutellarin on ischemic cerebral injury by down-regulating the expression of angiotensin-converting enzyme and AT1 receptor. PLoS One. 2016;11: e0146197. doi:10.1371/journal.pone.0146197

48. Deng YF, Aluko RE, Jin Q, Zhang Y, Yuan LJ. Inhibitory activities of baicalin against renin and angiotensin-converting enzyme. Pharm Biol. 2012;50:401-406. doi:10.3109/13880209.2011.608076

49. Yi L, Li Z, Yuan K, et al. Small molecules blocking the entry of severe acute respiratory syndrome coronavirus into host cells. $J$ Virol. 2004;78:11334-11339. doi:10.1128/JVI.78.20.11334-11339.2004

50. Schwarz S, Wang K, Yu WJ, Sun B, Schwarz W. Emodin inhibits current through SARS-associated coronavirus 3a protein. Antiviral Res. 2011;90:64-69. doi:10.1016/j.antiviral.2011.02.008

51. Schwarz S, Sauter D, Wang K, et al. Kaempferol derivatives as antiviral drugs against the $3 \mathrm{a}$ channel protein of Coronavirus. Planta Med. 2014;80:177-182. doi:10.1055/s-0033-1360277

52. Cheng PW, Ng LT, Chiang LC, Lin CC. Antiviral effects of saikosaponins on human coronavirus $229 \mathrm{E}$ in vitro. Clin Exp Pharmacol Physiol. 2006;33:612-616. doi:10.1111/j.1440-1681.2006.04415.x
53. Chen CJ, Michaelis M, Hsu HK, et al. Toona sinensis Roem tender leaf extract inhibits SARS coronavirus replication. J Ethnopharmacol. 2008;120:108-111.

54. Ryu YB, Park SJ, Kim YM, et al. SARS-CoV 3CLpro inhibitory effects of quinone-methide triterpenes from Tripterygium regelii. Bioorg Med Chem Lett. 2010;20:1873-1876. doi:10.1016/j. bmcl.2010.01.152

55. Ryu YB, Jeong HJ, Kim JH, et al. Biflavonoids from Torreya nucifera displaying SARS-CoV 3CLpro inhibition. Bioorg Med Chem. 2010;18:7940-7947. doi:10.1016/j.bmc.2010.09.035

56. Schmidtke M, Meier C, Schacke M, et al. Antiviral activity of phenolic polymers and cycloSal-pronucleotides against a SARS-associated coronavirus. Chemother J. 2005;14:16-21.

57. Chen LR, Wang YC, Lin YW, et al. Synthesis and evaluation of isatin derivatives as effective SARS coronavirus 3CL protease inhibitors. Bioorg Med Chem Lett. 2005;15:3058-3062. doi:10.1016/j.bmcl.20 05.04 .027

58. van de Sand L, Bormann M, Alt M, et al. Glycyrrhizin effectively inhibits SARS-CoV-2 replication by inhibiting the viral main protease. Viruses. 2021;13(4):609. doi:10.3390/v13040609

59. Lu H. Drug treatment options for the 2019-new coronavirus (2019nCoV). Biosci Trends. 2020;14(1):69-71. doi:10.5582/bst.202 0.01020

60. Science CAo. Researchers in Shanghai Institute of Drugs and Wuhan Virus Institute discovered that the Chinese patent medicine Shuanghuanglian oral liquid can inhibit the 2019-new coronavirus; 2020.

61. Chen X, Howard OM, Yang X, Wang L, Oppenheim JJ, Krakauer T. Effects of Shuanghuanglian and Qingkailing, two multi-components of traditional Chinese medicinal preparations, on human leukocyte function. Life Sci. 2002;70:2897-2913. doi:10.1016/S0024-3205(02)01541-2

62. Chan MC, Chan RW, Mok CK, Mak NK, Wong RN. Indirubin-3'oxime as an antiviral and immunomodulatory agent in treatment of severe human influenza virus infection. Hong Kong Med J. 2018;24 (Suppl 6):45-47.

63. Ding Y, Zeng L, Li R, et al. The Chinese prescription lianhuaqingwen capsule exerts anti-influenza activity through the inhibition of viral propagation and impacts immune function. BMC Complement Altern Med. 2017;17:130. doi:10.1186/s12906-017-1585-7

64. Poon PM, Wong CK, Fung KP, et al. Immunomodulatory effects of a traditional Chinese medicine with potential antiviral activity: a selfcontrol study. Am J Chin Med. 2006;34:13-21. doi:10.1142/ S0192415X0600359X

65. Li S, Chen $\mathrm{C}$, Zhang H, et al. Identification of natural compounds with antiviral activities against SARS-associated coronavirus. Antiviral Res. 2005;67:18-23. doi:10.1016/j.antiviral.2005.02.007

66. National Health Commission of the People's Republic of China. Transcript of press conference in 17, February, 2020; 2020. Available from: http://www.nhc.gov.cn/xcs/s3574/202002/f12a62d10c2a48c6895 cedf2faea6e1f.shtml. Accessed November 8, 2021.

67. National Health Commission of the People's Republic of China. Notice on the issunance of guidelines of diagnosis and treatment for 2019-nCoV infected pneumonia (version 6). 6 ed; 2020. Available from: http://www.nhc.gov.cn/yzygj/s7653p/202002/ 8334a8326dd94d329df351d7da8aefc2.shtml?from=timeline. Accessed November 8, 2021.

68. Han YY, Zhao MR, Shi B, et al. Application of integrative medicine protocols on treatment of coronavirus disease 2019. Chi Tradit Herbal Drugs. 2020;1-5:878-882.

69. Zhu YG, Deng ZW, Liu LH, et al. Compilation of drug information for the diagnosis and treatment of COVID-19 (version 1). Cent South Pharm. 2020;31-14.

70. Luo H, Tang QL, Shang YX, et al. Can Chinese medicine be used for prevention of corona virus disease 2019 (COVID-19)? A review of historical classics, research evidence and current prevention programs. Chin J Integr Med. 2020;26(4):243-250. doi:10.1007/ s11655-020-3192-6 
71. Xu X, Zhang Y, Li X, Li XX. Analysis on prevention plan of Corona virus disease-19 (COVID-19) by traditional Chinese medicine in various regions. Chin Herb Med. 2020;34:1-7.

72. Zhao J, Tian SS, Yang J, Liu J, Zhang WD. Investigating the mechanism of Qing-Fei-Pai-Du-Tang for the treatment of Novel Coronavirus Pneumonia by network pharmacology. Chin Herb Med. 2020;3:1-7.

73. Yao KT, Liu MY, Li X, Huang JH, Cai HB. Retrospective clinical analysis on treatment of novel coronavirus-infected pneumonia with traditional Chinese Medicine Lianhua Qingwen. Chin J Exp Tradit Med Form. 2020;45:1-7.

74. Lu RB, Wang WJ, Li X. Treatment of suspected new coronavirus pneumonia with Chinese medicine Lianhua Qingwen Clinical observation of 63 suspected cases. J Tradit Chin Med. 2020;3:1-5.

75. Zhang JW, Hu X, Jin PF. Cytokine storms caused by 2019-nCoV and drug therapy. Chin Pharm J. 2020;96:1-9.

76. Wang J, Qiao LF, Li YS, Yang GT. Shen Fu injection activate the macrophage NF-kB of rats' alveolar induced by LPS. Acta Medicinae Universitatis Scientiae et Technologiae Huazhong. 2009;1:15-18.

77. Chang XJ, Xiao W, Zhang S, et al. Mechanism of Re Du Ning injection on anti-acute lung injury in rats based on cytokines storm. Chin Herb Med. 2014;46:236-239.
78. Zou HM, He TZ, Chen X. Tetrandrine inhibits differentiation of proinflammatory subsets of $\mathrm{T}$ helper cells but spares de novo differentiation of iTreg cells. Int Immunopharmacol. 2019;69:307-312. doi:10.1016/j.intimp.2019.01.040

79. Chen H, Du Q. Potential natural compounds for preventing 2019-nCoV infection. Preprints. 2020. doi:10.20944/preprints2020001.0358

80. Zhang F, Huang J, Liu W, et al. Inhibition of drug-metabolizing enzymes by Qingfei Paidu decoction: implication of herb-drug interactions in COVID-19 pharmacotherapy. Food Chem Toxicol. 2021;149:111998. doi:10.1016/j.fct.2021.111998

81. Zhao J, Tian S, Lu D, et al. Systems pharmacological study illustrates the immune regulation, anti-infection, anti-inflammation, and multiorgan protection mechanism of Qing-Fei-Pai-Du decoction in the treatment of COVID-19. Phytomedicine. 2021;85:153315. doi:10.1016/j.phymed.2020.153315

82. Yu S, Zhu Y, Xu J, et al. Glycyrrhizic acid exerts inhibitory activity against the spike protein of SARS-CoV-2. Phytomedicine. 2021;85:153364. doi:10.1016/j.phymed.2020.153364

83. Huang YF, Bai C, He F, Xie Y, Zhou H. Review on the potential action mechanisms of Chinese medicines in treating Coronavirus Disease 2019 (COVID-19). Pharmacol Res. 2020;158:104939. doi:10.1016/j.phrs.2020.104939

\section{Publish your work in this journal}

Infection and Drug Resistance is an international, peer-reviewed openaccess journal that focuses on the optimal treatment of infection (bacterial, fungal and viral) and the development and institution of preventive strategies to minimize the development and spread of resistance. The journal is specifically concerned with the epidemiology of antibiotic resistance and the mechanisms of resistance development and diffusion in both hospitals and the community. The manuscript management system is completely online and includes a very quick and fair peerreview system, which is all easy to use. Visit http://www.dovepress.com/ testimonials.php to read real quotes from published authors. 